\title{
Quando o carnaval chegou: ativismo político no anverso histórico do Homo ludens
}

[ When carnival started: political activism in the historic obverse of Homo ludens

\author{
Francisco Mata Machado Tavares ${ }^{\mathrm{I}}$
}

Ellen Ribeiro Veloso ${ }^{2}$

Os autores agradecem à equipe do Núcleo de Pesquisas Proluta/UFG, em especial a Lira Furtado Moreno, pelas contribuições aos estudos que fundamentam este artigo.

\begin{abstract}
RESUMO.O debate filosófico sobre a pertinência da categoria hegelo-marxista da alienação, em terras brasileiras, não se contém no âmbito estritamente conceitual, revelando-se de maneira significativa sua dimensão fática. O filósofo Vilém Flusser, por exemplo, valeu-se dos atributos sócio-históricos da sociedade brasileira para tecer uma crítica ao conceito de alienação e, assim, justificar a sua tese de que há no marxismo hegeliano um universalismo que não contempla realidades como a do Brasil. Este artigo se propõe a reavaliar o diagnóstico apresentado por Flusser, de modo a infirmar, a partir de um estudo de caso centrado na greve dos garis de 2014 no Rio de Janeiro, a generalização de que o brasileiro seria o Homo ludens, cuja realidade se manifesta na alienação. Sugere-se, assim, uma interpretação alternativa para a relação entre o lúdico e o político no Brasil e, por via oblíqua, a reabilitação da noção hegeliana de alienação em face da crítica fenomenológica que Flusser lhe confere. P PALAVRAS-CHAVE - Homo ludens; Vilém Flusser; alienação; greve dos garis; ativismo. · ABSTRACT · Philosophy's debate
\end{abstract}

over the hegel-marxian concept of alienation in Brazil trespasses the border of a merely conceptual issue, and reveals a relevant factual dimension. The philosopher Vilém Flusser, for example, took the social-historical features of Brazilian society in order to depict a critique against the category "alienation" and therefore warrant the conclusion that hegel-marxism is embedded in an universalism that does not match specific realities, such as the Brazilian. This article is aimed at reevaluate this Flusser's diagnosis by the means of a case-study focused on the sweepers' strikes that took place in Rio de Janeiro in 20I4. We argue that the generalization of Brazilian as the Homo ludens, whose reality occurs in alienation, does not match the historical events we discuss. It is suggested an alternative interpretation for the relation between the "playful" and the "political”, and thus we obliquely rehabilitate Hegel's notion of alienation from Flusser's phenomenological critique. • KEYWORDS · Homo ludens; Vilém Flusser; alienation; street sweeper's strike; activism.

Recebido em I4 de setembro de 2015

Aprovado em I2 de julho de 2016

TAVARES, Francisco Mata Machado; VELOSO, Ellen Ribeiro. Quando o carnaval chegou: ativismo político no anverso histórico do Homo ludens. Revista de Estudos Brasileiros, Brasil, n. 64, p. 224-248, ago. 2016.

DOI: http://dx.doi.org/IO.II606/issn.23I6-90IX.voi64p224-248

I Universidade Federal de Goiás (UFG, Goiânia, GO, Brasil).

2 Universidade Federal de Goiás (UFG, Goiânia, GO, Brasil). 


\section{INTRODUÇÃo}

A noção de intervalo ou recesso cívico-político acompanha inúmeros discursos interpretativos, descritivos, estético-expressivos e fenomenológicos dedicados às formas de socialização especificamente brasileiras. Há um relativo consenso, em especial, quanto à definição do carnaval - particularmente naquelas localidades onde a festa ocorre de modo mais intenso, como a cidade do Rio de Janeiro - e do futebol - acentuadamente durante os períodos em que se promove o Campeonato Mundial da Fifa - como exemplos arquetípicos de intervalo na vida e nos problemas cotidianos da população brasileira.

Tal interpretação sobre o sentido social do futebol e do carnaval foi conduzida ao paroxismo pelo filósofo Vilém Flusser. Em sua obra Fenomenologia do brasileiro ${ }^{3}$, esses dois momentos ou eventos da cultura nacional, somados aos jogos lotéricos, são empregados como principais signos de um construto identificado sob o nome de Homo ludens ${ }^{4}$. Tal termo apontaria, a um só tempo, para a refutação do que se entende como um "historicismo" próprio à categoria "alienação" em sua apresentação hegelo-marxista. Conformaria, com efeito, um "novo homem”, "não histórico",

3 FLUSSER, Vilém. Fenomenologia do brasileiro. Organização de Gustavo Bernardo. Rio de Janeiro: UERJ, I998. Transcrição literal disponível em: 〈http://textosdevilemflusser.blogspot.com.br/〉. Acesso em: Io jul. 20I4.

4 O conceito de Homo Ludens não é indígena da obra de Flusser. Johan Huizinga desenvolveu a noção, lastreado em uma erudita plêiade de exemplos históricos, como alternativa à associação entre humanidade e racionalidade inscrita na categoria Homo sapiens e entre seres humanos e produção fabril pressuposta no Homo faber. HUIZINGA, Johan. Homo ludens. Tradução de João Paulo Monteiro. São Paulo: Perspectiva, 200o. O filósofo tcheco aqui discutido analisa noções formuladas pelo autor holandês citado, ao lidar com um elemento lúdico que não apenas predica ou se insere na cultura humana, mas a define. Flusser, todavia, se aparta de Huizinga ao acrescentar ao seu Homo ludens o elemento da a-historicidade, que é, precisamente, o que aqui se pretende problematizar. O cerne da abordagem teórica apresentada neste artigo diz respeito, portanto, ao Homo ludens de Flusser na condição de refutação lastreada em uma fenomenologia do brasileiro contra a noção hegelo-marxista de história. Não se trata, assim, de uma infirmação da noção em sua aparição primeira. 
específico do solo brasileiro e indisfarçavelmente concebido em tom laudatório pelo pensador tcheco 5 .

Em aparente descompasso com as acepções até aqui parafraseadas, o Brasil foi acometido, desde o ano de 20I3, por episódios de inequívoca politização em contextos de futebol e carnaval. Quanto à luta política em tempos de competição futebolística, basta mencionar a torrente de manifestações multitudinárias que ganharam as ruas de incontáveis cidades durante a Copa das Confederações da Fifa e que tiveram precisamente no evento - preparatório para o Campeonato Mundial - um dos seus principais temas e objetos de repúdio ${ }^{6}$. No que concerne ao carnaval, um impactante movimento grevista organizado por profissionais de limpeza urbana na cidade do Rio de Janeiro parece ter desafiado a tese de que os dias de festa e de samba são um intervalo em que lutas e demandas políticas não adquirem densidade social, visibilidade midiática ou força organizativa.

Este texto parte do último evento acima mencionado. A pergunta que orienta a pesquisa aqui relatada questiona se o movimento conhecido como "greve dos garis", na condição de exemplar relevante do contexto de reconfiguração do ativismo no Brasil que tem lugar ao menos desde $2013^{7}$, não desautorizaria sócio-historicamente a plausibilidade do tipo flusseriano do Homo ludens e, igualmente, a sua utilização como elemento de rechaço ao conceito hegelo-marxista de alienação.

Trata-se de um estudo de caso ancorado em dados secundários advindos, principalmente, de veículos de comunicação de massa. A partir dessas informações e do respectivo cotejo com o material bibliográfico abordado, empreende-se uma reflexão teórica afiliada à vertente contextualista sócio-histórica. Tal corrente metodológica, esposada por autoras como Ellen Wood, define-se pela dupla preocupação de, primeiramente, entender qual é a pergunta que motiva a contribuição teórica discutida e, adicionalmente, qual é o pano de fundo social e quais são os conflitos e tensões que pautam o contexto histórico em que a referida pergunta se erige ${ }^{8}$. Para alcançar esses propósitos, este texto se decompõe em quatro seções.

$\mathrm{Na}$ segunda seção, que segue esta introdução, são expostos os contornos do conceito flusseriano de Homo ludens e sua direta relação com o carnaval e o futebol. Apresenta-se, nesse contexto, a crítica do autor à noção hegelo-marxista de "alienação" e a recorrência ao brasileiro como contraprova factual da universalidade dessa categoria, ou como prova de sua reconciliação com a ideia de realidade.

A terceira seção apresenta e narra os eventos atinentes à "greve dos garis" no

5 Cf. FLUSSER, Vilém, op. cit.

6 Cf. SINGER, André. Brasil, junho de 20I3: classes e ideologias cruzadas. Novos Estudos: Cebrap, n. 97, nov. 20I3, p. 23-40. SAMPAIO JÚNIOR, Plínio de Arruda. Jornadas de junho e revolução brasileira. Interesse nacional, São Paulo, ano 6, n. 23, out.-dez., 2013, p. 57-66.

7 BRINGEL, Breno; PLEYERS, Geoffrey. Junho de 20I3... Dois anos depois: polarização, impactos e reconfiguração do ativismo no Brasil. Nueva Sociedad: Democracia e Politica en América Latina, volume especial, nov. 2015. Disponível em 〈http://nuso.org/media/articles/downloads/COY__Bringel_Pleyers.pdf 〉. Acesso em: I2 dez. 2015. $8 \mathrm{Cf}$. WOOD, Ellen. Liberty and property: a social history of western political thought from the Renaissance to Enlightenment. Londres: Verso, 2012. 
carnaval carioca de 20I4. A ideia é identificar e extrair as conclusões teóricas das possíveis discrepâncias entre esse carnaval e o que o "novo homem" de Vilém Flusser deveria sugerir.

A quarta seção avança, uma vez concluída a abordagem de uma sucessão de eventos que tensionam a plausibilidade do Homo ludens, para discutir a relação entre estética e ativismo político, de modo a argumentar em favor de uma linha teorética, assumidamente eclética, mas homogeneizada por um só espírito crítico, para a qual fantasias, cânticos, práticas miméticas e abstrações líricas não se definem como um mundo alienado ou irreconciliável com a noção marxista (e, em menor medida, também hegeliana) de consciência como anverso da alienação.

\section{VilÉm FlusSER, O HOMO LUDENS E O CARNAVAL: O CONTEXTO AUTORAL DE FENOMENOLOGIA DO BRASILEIRO}

A crítica fenomenológica de Flusser ao que identifica como pensamento "histórico", próprio à cultura ocidental em seu legado judaico-cristão, encontra no brasileiro, chamado de "novo homem", "não histórico", um ostensivo referente`. Antes, porém, de se aventurar por uma leitura sobre as peculiaridades da sociedade brasileira, o autor se apressa em apresentar a a própria perspectiva, auxiliando, sobremaneira, o trabalho de quem pretende lê-lo sob lentes contextualistas sócio-históricas.

Flusser posiciona-se com clareza e precisão em relação às distinções de origem e de classe que impactam o olhar do fenomenólogo sobre o respectivo objeto. Declara-se o filósofo, que era de origem tcheca e vivera no Brasil entre I94I e I972, como "um intelectual burguês, proveniente da cultura ocidental no final do século $\mathrm{XX}$ "ᄁo .

A atitude do autor em relação ao próprio processo criativo também é proposta ao público de maneira transparente. Avesso à mera descrição ou à ambição da neutralidade no discurso filosófico, Flusser é enfático em propor que "todo desengajamento ou serve de trampolim a um engajamento ou é irresponsável”ז A Fenomenologia do brasileiro, redigida em I972, ano em que o autor deixou o Brasil, adota a primeira variante de desengajamento acima apresentada (a única realmente honesta, para o juízo do autor), de modo a voltar-se para "oferecer ao leitor um ponto de vista, a partir do qual poderá ver, de um ângulo determinado, a situação na qual estamos e acrescentar a visão resultante a outras visões para poder orientar-se"ז2.

É certo que a cautelosa perspectiva de quem pretende oferecer uma visão, dentre outras possíveis, sobre o Brasil e o brasileiro, mitiga-se em uma nada modesta consideração preliminar. Ocorre que, para Flusser, a consciência de estar perdido é a negação e condição dialética da necessidade de orientar-se. Em suma,

9 O escopo deste artigo refoge da abordagem pormenorizada do solo filosófico em que a complexa e autêntica obra flusseriana viceja. Esta seção, portanto, atém-se a apresentar o conceito de Homo ludens formulado pelo autor, o que demanda uma incursão apenas limitada no contexto mais amplo dos estudos que conduz.

Io FLUSSER, Vilém, op. cit.

II Ibidem.

I2 Ibidem. 
o livro aqui discutido é produzido por alguém que firma uma antropologia do ser humano livre sobre o reconhecimento da perdição e do deslocamento para, em seguida, apresentar-se como o referente dessa condição no que tange ao Brasil. Denota-se, assim, uma reivindicação de privilégio epistêmico para o olhar que será dedicado ao objeto da obra. Percebe-se, desse modo, uma ambígua autoimagem no autor de Fenomenologia do brasileiro. Ela oscila de modo a cultivar, por um lado, uma peremptória negação da possibilidade de apresentar não mais do que uma visão, parcial e limitada como todas, sobre o país. Por outro, parece habitar o eterno e guardar um fôlego totalizante, ao apresentar-se como alguém que está concomitantemente na história e na não história, sem desesperar-se de nenhuma delas ${ }^{\mathrm{I3}}$.

Em resumo, a meta do autor é oferecer um olhar estrangeiro, entendido como especialmente promissor, já que reconhecidamente perdido, sobre o Brasil. Nas palavras de Flusser, seu ensaio sobre o Brasil parte de uma condição subjetiva de angústia e de distanciamento, de modo que "assume um ponto de vista específico, procura projetar daí uma imagem da situação, na esperança de que tal imagem possa servir, em conjunto com outras, a uma orientação na situação e de trampolim para a sua modificação - portanto, para um engajamento"ז4.

Com vistas a aplicar a dialética flusseriana ao próprio autor, o presente artigo, como adiante ficará mais claro, aceita a oferta acima transcrita. Ao mesmo tempo, devolve aos pressupostos de engajamento fornecidos pelo olhar distanciado do estrangeiro imigrado o engajamento efetivo como pressuposto do olhar nativo, que pode emigrar na condição de repertório de ação política capaz de irradiar um frescor de riqueza estética e de autonomia classista às formas de protesto social sedimentadas nos arranjos corporativos que a Europa social-democrata ensinou ao mundo.

\section{A NÃO HISTÓRIA FLUSSERIANA E A NOITE EM QUE TODOS OS GATOS UNIVERSALISTAS SÃO TEOLOGICAMENTE PARDOS}

A tese forte subjacente ao discurso fenomenológico sobre o futebol, a loteria e o carnaval brasileiros em Flusser é a infirmação da universalidade do conceito hegelo-marxista de alienação. Assim, a abordagem sobre o jogo e a festa no país se revela como meio para que se exponha um argumento apontado para a tradição filosófica que o autor caracteriza como "historicista".

Flusser entende a história como uma projeção universal, acompanhada de narrativas que escolhem determinados momentos como "decisivos", circunscrita a um breve (pois concentrado sobre menos de $2 \%$ da trajetória da espécie humana) epiciclo de 8.000 anos, ocorrente entre os graus 25 e 60 do hemisfério norte ${ }^{15}$. A "não história" amalgamaria, por um lado, o que se define como "pré-história", que aglutinaria da crítica de esquerda ao conservadorismo europeu e seria concebida pelo "historicismo"

\footnotetext{
I3 Ibidem.

I4 Ibidem.

I5 Ibidem.
} 
como algo a se superar por meio do "desenvolvimento" ou "avanço". Por outro lado, o filósofo em questão interessa-se em identificar na "pré-história" uma verdade recôndita de "pós-história", ou seja, de superação da humanidade própria ao epiciclo cuja narrativa se faz dominante. O Brasil, para Flusser, seria um notável exemplo de sociedade não histórica, com potencial, destarte, para fazer germinar um "novo homem", "pós-histórico".

Sobre o solo social brasileiro, as categorias mais relevantes do modo historicizante de se pensar entram, segundo o juízo de Flusser, em colapso. Um exemplo de conceito que não operaria nesta parte do planeta de modo equivalente ao que se dá na Europa seria a ideia de alienação. Segundo o pensador tcheco, que viveu um trintênio no Brasil, a noção filosófica de alienação revela, para além do seu imediato elemento epistêmico e ontológico, aspectos éticos, psicológicos e religiosos.

Alienar-se, na obra em comento, é perder-se do "ser abrigante". As filosofias que visam à superação dessa condição seriam aquelas que tentariam devolver o humano para a totalidade ou abrigo perdidos, seja na forma de natureza, seja na do espírito absoluto. A conformação judaico-cristã, escatológica e soteriológica da categoria, com efeito, far-se-ia notar até mesmo em suas mais seculares variantes.

Em Hegel, por exemplo, Flusser identifica um sistema especulativo debruçado sobre o passado. Em Marx, vê-se processo análogo, mas debruçado sobre o futuro. De qualquer modo, a superação da alienação é, em ambos, problema circunscrito ao olhar historicizante, que "transforma toda a história em história sacra"16. Em poucas linhas e com equiparações de ordem formal, Flusser compara "a exigência de que abandonem uma condição que precisa de ilusões" ${ }^{\prime 7}$ à teologia judaica e suas quimeras. Ao reduzir uma vasta e multifacetada tradição do pensamento humano ao critério da busca ou identificação de uma universalidade - que, em Flusser, não importa se é concreta ou abstrata - chega-se à máxima de que "todo pensamento histórico tem base teológica, a saber, judia, e que o Ocidente continua basicamente cristão, não a despeito mas por causa do marxismo" 18 .

Antes de avançar sobre a dimensão factual da crítica flusseriana - i.e., o brasileiro como contraprova da ideia hegelo-marxista de alienação -, duas ponderações são necessárias. Equiparar, sem mais, judaico-cristianismo a Hegel e, em seguida, a Marx, é uma empreitada filosófica que demanda a desconsideração, como incidentes ou pontuais, de rupturas e inovações por demais drásticas para serem tomadas em tão reducionista conta.

Hegel, por exemplo, finca-se sobre uma antropologia judaico-cristã, à qual

I6 Ibidem.

I7 MARX, Karl. A crítica da filosofia do direito de Hegel. Tradução de Rubens Enderle e Leonardo de Deus. São Paulo: Boitempo, 2005, p. I46.

I8 FLUSSER, Vilém, op. cit.A associação entre as filosofias de Hegel e Marx com a escatologia judaico-cristã não é uma marca exclusiva da obra de Flusser. Como o filósofo tcheco, outros pensadores esposam compreensões dessa natureza. Confira-se, a propósito, um artigo de David Byrne em que Marx é entendido como uma espécie (acompanhada de Hegel) de filósofo do século XIX cujo pensamento impregna-se de um milenarismo cuja matriz estaria no Apocalipse de João. BYRNE, David T. The victory of the proletariat is inevitable: the millenarian nature of marxism. Kritike, v. 5, n. 2, dec. 20II, p. 59-67. 
remete, expressamente, a gênese da sua noção de espírito (Geist). As semelhanças, todavia, param aí. O pensamento efetivamente histórico não pode ser judaico-cristão, porquanto a historicidade, a liberdade e a consciência do humano devem operar no mundo, antes de se remeterem ao eterno, divino, por si só estático, anti-histórico, como se sabe desde a escolástica agostiniana ${ }^{\text {I9 }}$. Equiparar o pensamento histórico de Hegel à teologia e sua escatologia, como faz Flusser, implica uma desconsideração da crucial circunstância de que a história teológica não é, afinal, histórica, porque jaz sob o eterno. Como afirma Kojève:

Se [...] Hegel se afasta da tradição filosófica pagã e aceita a tradição antropológica judaico-cristã, ele enfatiza no mesmo texto que também se desliga desta última tradição num ponto de extrema importância filosófica.

É que a tradição antropológica judaico-cristã é uma tradição essencialmente religiosa e até teísta (e teológica). [...]

Ora, segundo Hegel, o ser espiritual ou dialético é necessariamente temporal e finito. [...]

O absoluto-espírito ou a substância-sujeito, a que Hegel se refere, não são Deus. O Espírito hegeliano é a totalidade espaçotemporal do mundo natural que implica o discurso humano revelador do mundo e de si mesmo ${ }^{20}$.

Há que se considerar a condição sócio-histórica da qual parte o pensamento de Flusser: trata-se de um intelectual que se declara como burguês e, como tal, não pretende irromper para além da alienação própria do indivíduo entregue à sua singular sorte na sociedade ocidental-liberal, senão por meio de um Deus externo e eterno. Assim, toda rota de liberação da alienação subiria aos céus. Em Hegel, como em Marx, é na coletividade humana que se encontra a realização do ser. A liberdade, de um modo que avança sobre Rousseau e Fitche, acontece no plural. Tal linha de entendimento, contudo, não cabe no individualismo próprio ao solo filosófico que informa o pensamento de Flusser.

Se a negação da ideia de alienação por meio de uma equiparação entre Hegel e a escatologia teológica incorre nos intransponíveis limites acima expostos, quando

I9 O pensar teológico assume a história, mas a reduz e, enfim, dissolve em outro plano, eterno, aquele que tudo cria e determina. Entre a teologia do cristianismo e Hegel, há uma entrega da humanidade a si que aquela, como o trecho a seguir indica, jamais autorizaria: "os Vossos anos não vão nem vêm. Porém os nossos vão e vêm, para que todos venham. Todos os Vossos anos estão conjuntamente parados, porque estão fixos, nem os anos que chegam expulsam os que vão, porque estes não passam. [...] Os Vossos anos são como um só dia, e o Vosso dia não se repete de modo que possa chamar-se quotidiano, mas é um perpétuo hoje, porque este vosso hoje não se afasta do amanhã, nem sucede ao ontem. O vosso hoje é a eternidade”. SANTO AGOSTINHO. Confissões. Tradução de J. Oliveira Santos e A. Ambrósio de Pina. Bragança Paulista: São Francisco, 2003, p. 278.

20 KOJÈVE, Alexandre. Introdução à leitura de Hegel. Tradução de Estela dos Santos Abreu. Rio de Janeiro: Contraponto, 2002, p. 502-503. 
se trata de subsumir Marx ao cristianismo, as lacunas e imprecisões flusserianas se tornam ainda mais evidentes. Ocorre que, em Hegel, ainda é possível notar que a universalidade humana (coletividade, unidade da espécie/Gattung) tem natureza abstrata, ainda que objetiva, e se realiza no céu da ideia objetiva estatal, antes de manifestar-se na concretude da vida efetivamente experimentada pela humanidade. Em Marx, contudo, dá-se um passo adiante ${ }^{21}$. A partir das formas abstratas de universalidade da espécie (Gattung), o autor parte em busca de uma universalidade concreta e a encontra nas relações sociais de produção.

A ruptura marxista com a ideia de universalidade abstrata (religião, direito, capital etc.) em favor da universalidade concreta (experimentada nas relações sociais de objetificação das ideias em um meio, ou seja, nas relações de produção) é crucial, como destaca Andrew Chitty:

Se a característica essencial dos seres humanos, para Marx, é a universalidade, então é esta a "universalidade abstrata" de Hegel ou sua "universalidade concreta”, ou seja, é uma universalidade que é oposta à particularidade ou é uma combinação de universalidade e particularidade? Em A ciência da lógica Hegel explicitamente associa a ideia de universalidade concreta ao termo "espécie” (Gattung), de modo que a escolha de Marx do termo "ser genérico" (species being; Gattungwesen) já indica que ele tem a universalidade concreta em mente [...]. A visão de Marx de uma sociedade que realiza a universalidade humana é aquela na qual cada indivíduo realiza a universalidade em seu trabalho individual e em suas relações individuais ${ }^{22}$.

Flusser não adentra o debate acima e procura reduzir o conceito de alienação à mera busca por um ser abrigante, por uma totalidade qualquer. Descuida-se, assim, de perceber que a superação da alienação em Deus (eterno), em universalidades abstratas (como o Estado) ou em universalidades concretas (relações sociais de produção) não encerra diferenças apenas incidentais, mas antipódicas, de modo que a não alienação nos cristãos, ou mesmo em Hegel, significa a mais alienante das formas de vida em Marx. Em um texto focado sobre a concretude urbana do Brasil nos anos 70 do século $\mathrm{XX}$, repleto de exemplos e alusões à economia e à política mundanas, reduzir toda crítica à condição alienada do humano como uma forma mais ou menos secular de teologia é uma operação lógico-reducionista que pode inviabilizar a validade do próprio argumento - histórico e pautado em dados da concreta realidade - erigido pelo autor.

É sobre essas premissas filosóficas e sobre esse tão amplo conceito de alienação que a obra Fenomenologia do brasileiro avança para identificar um "novo homem" que se encontra e se realiza em um tipo de fuga que, alhures, seria apenas alienante, irreal. A subseção seguinte pormenoriza esse tema.

2I Na sagaz síntese de Bernard Bourgeois, "o marxismo se apresentará como a verdade do hegelianismo". BOURGEOIS, Bernard. O pensamento político de Hegel. Tradução de Paulo Neves da Silva. São Leopoldo: Unisinos, 2000, p. I48).

22 CHITTY, Andrew. Species-being and capital. In: CHITTY, Andrew \& IVOR, Martin (Ed.). Marxism and contemporary philosophy. Londres: Palgrave, 2009, p. I29. 


\section{O HoMO LUDENS E A REALIZAÇÃo DO BRASILEIRO NA FUGA}

O Brasil urbano da década de 70 do século XX, objeto perquirido por Flusser, é uma composição caleidoscópica e ambivalente de elementos redentores da humanidade, em meio a um cenário apocalíptico, desolador.

A cidade de São Paulo é, na impressão do autor, uma "aglomeração colossal" que "espalha-se qual doença de pele ou câncer" ${ }^{23}$. Trata-se de espaço acometido pela "instalação acidental” da indústria e pela "aglomeração igualmente acidental de imigrantes nordestinos" 24 . O cenário é de um "caos infernal manifestado por trânsito desumano, meios de comunicação em colapso e pandemônio geral”"25. Vê-se que, depois de se despedir do pensamento histórico e de equiparar Marx e Hegel à teologia cristã, o filósofo em questão não teve outra saída senão definir o processo de migração e de industrialização paulistanos como "acidentais", ignorando, destarte, todo o mecanismo histórico-explicativo que a ciência de historiadores como Caio Prado Júnior poderia fornecer.

A alienação do proletário brasileiro (um "caboclo urbanizado", para Flusser) seria diferente daquela experimentada pelo proletário da Europa e dos Estados Unidos da América. Aquele estaria alienado de forma exilada, como quem se sente expulso do seu lugar. Este, lado outro, estaria enquadrado na maquinaria burocráticofabril, como quem se sente preso. Essas diferentes variações da alienação irradiam consequências sobre o peculiar comportamento do proletário brasileiro. Como exemplo, o autor constata que "no rosto do proletário brasileiro alienado e miserável aparece um sorriso feliz muito mais prontamente do que no rosto do proletário aburguesado do Ocidente" ${ }^{26}$. A diferença entre as duas alienações é decomposta por Flusser em três espécies.

Primeiramente, o proletário europeu, dada a gênese "interna" da sua condição, buscaria soluções políticas por meio da respectiva representação no governo, com vistas à socialização. Já o proletário brasileiro, como tem uma alienação de gênese externa, associada a decisões tomadas sempre fora do país, vê o governo voltar-se à nacionalização, antes da socialização.

Uma segunda espécie de diferença entre o proletário do norte e o brasileiro residiria, para Flusser, no fato de que este não teria experimentado significativas lutas e adquirido, nesse processo, uma consciência própria à sua classe. O trabalhador urbano brasileiro, com efeito, sonharia os sonhos do burguês e neles projetaria sua identidade e autoimagem. Até mesmo as formas de organização de classe, como

\footnotetext{
23 FLUSSER, Vilém, op. cit.

24 Ibidem.

25 Ibidem.

26 Ibidem.
} 
sindicatos, seriam, no Brasil, nada mais do que figuras externas, estranhas à sua peculiar realidade ${ }^{27}$.

Em terceiro lugar, haveria a economia inflacionária. Como se sabe, o país descrito por Flusser vivia sobre uma estrutural realidade de constante e progressiva escalada dos preços. Diante desse problema macroeconômico, o autor nota uma forma de alienação concernente à ilusão do proletário de que cresce, progride e ascende socialmente, uma vez que, nominalmente, os salários sobem, ainda que o poder de compra não siga o mesmo caminho.

Como toda alienação, a condição do proletário brasileiro conduz a fugas e choques. Interessam a Vilém Flusser, em especial, as fugas, com destaque para as três mais representativas do Homo ludens que, em seguida, é explicado: futebol, loteria e carnaval.

O futebol para o brasileiro é, segundo Flusser, antes de mecanismo que leva ao esquecimento da realidade, como na experiência do italiano ou do inglês, uma realidade enquanto tal. O proletário brasileiro, assim, brinca e joga, mas o faz seriamente. Foge da miséria de uma vida alienada, mas, precisamente, nessa fuga, encontra uma realidade, "pelo menos tão real quanto a abandonada" ${ }^{28}$. Vive-se o futebol plenamente, torce-se por um time seriamente, encontra-se identidade, realização, felicidade, tragédia, enfim, vida, na lógica do jogo que, mais do que epifenômeno ou escape do "mundo real" é, para o proletário brasileiro, um mundo efetivo, real, sério.

A loteria, igualmente, antes de mecanismo de sonho ou de projeção alienada de um enriquecimento futuro e ilusório, encerra uma verdade intrínseca ao próprio jogo, em que a "alienação passa a ser, dialeticamente, nova realidade" 29 . As pessoas correm às filas das casas lotéricas não para ganhar, mas para jogar. Nas palavras de uma canção popular, logo após jogar na loteria, muito antes de saber se vencerá ou não, o brasileiro ri "porque rico ri à toa, também não custa nada imaginar". Em Flusser, o próprio jogo conta para o trabalhador urbano brasileiro e, no jogo, ele se realiza.

O carnaval, por sua vez, apesar de não se definir propriamente como jogo, mas brincadeira, estamparia com ímpar intensidade a fuga do ser alienado em direção a uma outra, igualmente real, situação. Os quatro dias de folia, segundo Flusser, põem "o resto do ano entre parênteses, de forma que desapareça existencialmente" ${ }^{\circ}$.

27 É também nesse sentido que Flusser chega à seguinte constatação: "O outro lado da dialética é que o marxismo prega o apego à situação concreta, mas a situação concreta não pode ser captada, no Brasil, por categorias marxistas. Resumindo a dialética da defasagem, neste caso, pode ser dito que, para ser marxista no Brasil, é necessário deixar-se de ser marxista”. Longe de consensual ou autoevidente, essa tese confronta, por exemplo, os cuidadosos estudos de Sweezy, para quem o proletariado do terceiro mundo na segunda metade do século XX "é revolucionário no mesmo sentido e pelas mesmas razões que Marx considerou o proletariado do nascente período das indústrias modernas como revolucionário”. SWEEZY, P. M. Marx and the proletariat. In: JESSOP, Bob (Ed.). Karl Marx’s social and political theory. v. 2. Londres: Routledge, I990, p. 240 (tradução nossa). 28 FLUSSER, Vilém, op. cit.

29 Ibidem.

30 Ibidem. 
Flusser entende a "realidade" da economia e das necessidades físicas como relevante e integrante da vida do brasileiro apenas porque, como mamífero, ele precisaria se alimentar e, assim, ter satisfeitos os imperativos fisiológicos da respectiva reprodução física, associada ao mundo do trabalho e da economia. Esta seria a concessão do autor à dimensão de "choque", antes de "fuga", própria à alienação do proletário no Brasil. A quarta-feira de cinzas traria a realidade "econômica" de volta, apresentando ao ser vivo os imperativos da sobrevivência.

Para além disso, todavia, momentos como o carnaval estampariam a profunda existência do Homo ludens, do novo homem brasileiro, daqueles que "não se esquecem da realidade, senão se descobrem a si mesmos e descobrem a realidade profunda não histórica que os sustenta, passando a viver nela" 3 . $\mathrm{O}$ autor é ainda mais peremptório e afirma, sem apresentar um lastro metodológico-etnográfico que respalde tão radical ideia, que "o proletário brasileiro tende a buscar sua felicidade no jogo, antes de ter satisfeitas as suas necessidades básicas”32.

A conclusão do autor, diante da constatação de que o futebol, a loteria e o carnaval seriam a realidade do brasileiro, a fuga que cria nova realização, antes de alienação, só pode ser a de que, neste país, a "cultura" seria infraestrutura, e a "economia", superestrutura.

Nota-se, na leitura acima sumarizada, duas limitações na argumentação do autor:

I) Reserva-se o econômico ao campo das necessidades de um ser que "sendo, entre outras coisas, mamífero, não pode ser feliz se não forem satisfeitas as necessidades básicas fisiológicas”33. Separa-se, assim, o campo da produção, das relações de produção, da distribuição e da reprodução material de qualquer interação simbólica ou comunicação que com ele poderia estar alinhavada dialeticamente. Fica fechada a via, por exemplo, para entender o conceito marxista de relações de produção como associado a relações recognitivas, no sentido que o Hegel de Jena e da Fenomenologia do espírito confere à ideia ${ }^{34}$.

2) Do problema acima, chega-se a uma segunda limitação. Ao aceitar, sem crítica, uma clivagem rígida entre infraestrutura e superestrutura - possível apenas nas interpretações mais apressadas e menos contextualizadas do conjunto da obra de Marx $^{35}$-, Flusser ainda avança para inverter uma relação que, em sua forma originária, já se fazia problemática quando assimilada de modo linear, não dialético, a partir de leituras mecânicas inadequadas para a compreensão de um pensamento crítico, como o marxista. Assim, sustenta-se que o jogo, o onírico, o humano que

\footnotetext{
3I Ibidem.

32 Ibidem.

33 Ibidem.

34 Cf. TAVARES, Francisco Mata Machado. Para além da democracia deliberativa: uma crítica marxista à teoria política habermasiana. Tese (Doutorado). Departamento de Ciência Política, Universidade Federal de Minas Gerais, 20I3. Disponível em 〈http://marxismo2I.org/estado-e-democracia/〉. Acesso em: I8 jun. 2014. 35 Ibidem.
} 
encontra nova realidade na fuga, justificariam a alegação de que "pode perfeitamente acontecer que no Brasil a economia não seja infraestrutura num sentido dialético, e cultura não seja superestrutura, mas que exatamente o contrário seja o caso"36.

Se o chamado para a relação marxista entre base e superestrutura já é, por si só, infenso a interpretações lineares ${ }^{37}$, sua inversão, em Flusser, a sugerir que a trama do futebol e o enredo do samba determinam a acumulação do capital e as relações econômicas, revela-se, quando menos, pouco crível. O ônus da prova, assim, recai sobre o filósofo do século XX que, porém, dele não se desincumbe.

De qualquer modo, a partir das bases acima expostas, a obra Fenomenologia do brasileiro vê duas tendências na realidade deste país. Por um lado, pode surgir um "novo homem", diferente do europeu, que permitiria ao brasileiro, em sua experiência lúdica não histórica, encontrar-se consigo e viver sua essência. Por outro lado, o Homo ludens poderia dissolver-se no ser histórico do Norte e degenerar-se em uma forma precária de vida que seria, aí sim, alienada e burocratizada. $O$ caso que será apresentado na seção seguinte, referente a um movimento grevista ocorrente em meio ao carnaval do Rio de Janeiro 32 anos após a publicação de Fenomenologia do brasileiro, indica que, na loteria do futuro nacional, Flusser parece ter perdido duplamente a sua aposta, já que o proletário do Brasil não sambou junto ao time dos intelectuais burgueses e comportou-se de modo equidistante em relação ao Homo ludens e ao europeu contido pela máquina burocrática e fabril.

\section{UM CARNAVAL DE LUTA: OS GARIS E O CENÁRIO ANTIFLUSSERIANO NO RIO DE JANEIRO EM 20I4}

Quem comparece à avenida Marquês de Sapucaí, onde fica o sambódromo da cidade do Rio de Janeiro, para ver o carnaval já se acostumou a uma prática que, ano após ano, se repete. Antes de ter início o desfile das escolas de samba, passam pela avenida aqueles que trabalham na grande festa que notabiliza a cidade mundialmente. Os trabalhadores da limpeza urbana, chamados de garis e reconhecidos por uniformes de um saliente tom alaranjado, são efusivamente aplaudidos, saudados pelo público. Renato Sorriso, um carismático gari que se consagrou por sambar para a plateia enquanto trabalha nos intervalos dos desfiles, chegou a ganhar notoriedade global ao se apresentar em Londres, por ocasião do encerramento dos Jogos Olímpicos de 2012. Essas pessoas, cujo empregador é a Prefeitura Municipal do Rio de Janeiro, são, em síntese, uma categoria profissional que encontra especial simpatia junto à população.

As condições de vida dos garis não coincidem com a sua imagem social de trabalhadores alegres. Com efeito, não podem ser descritos como miseráveis sorridentes e felizes, no sentido flusseriano acima apresentado. Em uma economia já estável sob o aspecto monetário - e eis aqui uma primeira diferença entre o Brasil

36 FLUSSER, Vilém, op. cit.

37 Cf. TAVARES, Francisco Mata Machado, op. cit.; WOOD, Ellen Meiksins. Democracy against capitalism. Renewing historical materialism. Cambridge: Cambridge University Press, I999; CHITTY, Andrew. Recognition and social relations of production. Historical Materialism, n. 2, Verão, I998, p. 57-97. 
atual e aquele abordado por Flusser-, os profissionais da limpeza urbana vivem sob penosa condição. No início de 20I4, esses trabalhadores, submetidos a condições insalubres, percebiam um salário-base mensal de $\mathrm{R} \$ 803,00$, equivalente, à época, a aproximadamente 250 euros. Trata-se de remuneração correspondente a um quarto da média recebida pelas demais categorias de servidores públicos municipais no Rio de Janeiro. Com todos os adicionais, alcançam-se vencimentos de R \$ I.220,00, ou aproximados 375 euros.

Irresignados com essas condições, os profissionais de limpeza urbana do Rio de Janeiro iniciaram, entre fevereiro e março de 20I4, com ápice durante o carnaval, um processo de mobilização em favor de reajuste salarial e por melhores condições de trabalho ${ }^{38}$. Sob um cenário em que a burocracia sindical ${ }^{39}$ não tomava a iniciativa reivindicatória, os garis estabeleceram comunicações informais por meio de redes sociais na internet, em particular o Facebook. A partir daí, convenceram a entidade sindical a realizar uma reunião com a categoria, o que ocorreu na sexta-feira precedente ao carnaval. Desse encontro, ressaiu a decisão por uma interrupção de 24 horas nas atividades de coleta de lixo e limpeza urbana, a ter lugar no sábado de carnaval. A direção sindical, todavia, retrocedeu em seu apoio à greve que, em seguida, fora judicialmente declarada como ilegal.

Os garis não se aquietaram diante das ofensivas do Poder Judiciário e do desprezo à sua causa ostentado pela burocracia sindical. Ao contrário, radicalizaram. Seguiram em greve e, valendo-se da condição física usualmente favorecida, própria a quem circula diuturnamente a recolher lixo e fazer varrição, engajaram-se em protestos que marchavam, sob o ritmo do carnaval, por toda a cidade.

O Rio de Janeiro, em meio à sua mais conhecida festa popular e no período em que recebe um grande fluxo de turistas - o carnaval -, ficou coberto de lixo. Sem os garis para recolherem todo o resíduo acumulado, as ruas da cidade rapidamente tornaram-se insalubres e nada confortáveis ao trânsito de blocos caricatos e veranistas.

A repressão não tardou em vir. Primeiramente, o prefeito municipal declarou que a greve era um movimento ilegal, conduzido por um ínfimo número de 300 garis, "marginais e delinquentes" plenamente coberta de lixo em uma greve com adesão minoritária, o gestor político

38 Um testemunho de Maria Paes, uma das líderes dos grevistas, indica a penosa condição em que os garis trabalham: "Os gerentes não respeitam ninguém. É assédio o tempo todo, ameaças. A gente não tem luva. Protetor solar, neste sol, eles não dão. A nossa gerência não tem água. A gente tem que beber água da bica. Quando a gente pede água a eles, eles mandam a gente comprar”. MANENTI, Caetano. Garis usam 4 dias de carnaval para movimento histórico no Rio de Janeiro. Sul 2I, 5 de março de 20I4. Disponível em: <http://www. sul2I.com.br/jornal/garis-usam-os-quatro-dias-do-carnaval-para-movimento-historico-no-rio-de-janeiro $>$. Acesso em: Io jul. 20I4.

39 O diretor-tesoureiro do sindicato é filiado ao PTB, partido da base aliada ao prefeito do Rio de Janeiro. A entidade não realiza eleições há I3 (treze) anos. Cf. GARCIA, Rafael Tsavko. Greve dos garis no Rio de Janeiro: da luta à vitória. Global Voices, 20I4. Disponível em: <http://pt.globalvoicesonline.org/20I4/o3/II/greve-de-garis-norio-de-janeiro-da-luta-a-vitoria $>$. Acesso em: Io jul. 2014.

40 Apud GARGIA, Rafael Tsavko, op. cit. 
caiu em nova contradição e ameaçou demitir, sumariamente, algo entre I.200 e 2.000 trabalhadores da limpeza urbana. De fato, centenas de demissões, efetivadas por meio de serviço de mensagem de telefones móveis - SMS - ocorreram, para, em poucos dias, serem revogadas em face da pressão já crescente em meio à opinião pública e aos garis, cada vez mais mobilizados.

Às demissões, somou-se a coerção policial. Sob o argumento de escoltarem trabalhadores que não queriam aderir à greve, policiais militares foram destacados para coagirem os garis a efetivarem a varrição das ruas. A cena, como muitos intelectuais notaram ${ }^{4 \mathrm{I}}$, fez lembrar o Brasil do século XIX, quando escravos eram conduzidos ao labor manu militari ${ }^{42}$. O quadro era ainda mais semelhante em função de a maioria dos proletários da limpeza pública do Rio de Janeiro ser composta por pessoas negras.

O movimento prosseguiu e, não obstante a coerção e os enquadramentos negativos apresentados nos grandes veículos de comunicação de massa ${ }^{43}$, angariou significativo apoio popular. Os protestos públicos obtiveram adesão crescente. Cordões de operários vestidos com uniforme alaranjado destacaram-se entre os mais frequentados e animados blocos carnavalescos do Rio de Janeiro em 2014. Percussões, marchinhas politizadas, estandartes, a adesão do famoso passista-gari Renato Sorriso, cartazes de tom lúdico-antilúdico como "o prefeito quer fazer a copa, os garis querem fazer as compras" e adesões de foliões que se juntavam à marcha proletária deram o tom da festa popular, embebida em protesto, ou do aguerrido protesto, imerso no festejo promovido pelos garis. O movimento, afinal, obteve

4I GARGIA, Rafael Tsavko, op. cit.

$42 \mathrm{O}$ ativista e videomaker Rafael Puetter chegou a documentar a situação em entrevista com trabalhador forçado a trabalhar. Ibidem.

43 O exemplo a seguir, referente a episódio ocorrido com um servidor público que concedeu entrevista a TV no contexto do carnaval, é emblemático. Ibidem. Confira-se: “A Globo cortou tudo que disse! Fica até parecendo que sou contra os garis! O repórter me fez duas perguntas (não recordo as palavras exatas): Repórter: Você está vendo muito lixo? Eu: Estou vindo lá da prefeitura, estava participando da manifestação dos garis e, realmente, é muito lixo mesmo, mas como funcionário público entendo o lado deles e dou total apoio às suas reivindicações. Repórter: Como você se sente vendo todo esse lixo? Eu: Percebo que a prefeitura disponibilizou poucas lixeiras e banheiros, além de não atender os pedidos legítimos dos garis. O que o Jornal Nacional coloca no ar? Apenas o trecho que digo 'é muito lixo'! Isso, dentro do contexto da reportagem, soa como se eu estivesse indignado com a greve dos garis, ou seja, o oposto da realidade.” Globo lixo! Link do vídeo: http://globotv.globo.com/rede-globo/ jornal-nacional/t/edicoes/v/imagens-de-lixo-nas-ruas-choca-moradores-e-turistas-no-rio-de-janeiro/3I90223/”. Declaração disponível em: 〈https://www.facebook.com/junior.felipebebel/posts/IOI5234I80I487650〉. Acesso em: Io jul. 20I4. Um colunista de orientação governista, Jânio de Freitas, escreveu em um jornal de grande circulação (Folha de S. Paulo) que "não se pode dizer que essa minoria usasse um direito ao persistir na greve, por 'não se sentir representada pelo sindicato' no entanto eleito pela categoria. O direito à greve deixou de existir quando a Justiça a declarou ilegal”. FREITAS, Jânio de. O papel da PM na greve dos garis. Blog do Nassif. I3/3/20I4. Disponível em: <http://jornalggn.com.br/noticia/o-papel-da-pm-na-greve-dos-garis-por-janio-de-freitas >. Acesso em: Io jul. 20I4. Naturalmente, ele não sabia que a entidade não realizava eleições desde 200 e, igualmente, que, se a legalidade fosse o critério da "existência" de greves, nada teria ocorrido no ABC Paulista entre o final da década de 70 e o início dos anos 80 do século XX. 
importantes conquistas. Em 8 de março, celebrou-se um acordo que garantiu um acréscimo do salário-base da categoria, que passou a valer R \$ I.IO0,00, acrescidos de novos direitos e parâmetros laborais igualmente concedidos pelo poder público.

O encadeamento fático acima narrado desafia a compreensão flusseriana do carnaval, indicando problemas e limites próprios à leitura antidialética e anti-histórica albergada pelo autor tcheco. Uma breve referência a leituras alternativas é suficiente para indicar que não a dinâmica lúdica do carnaval e o protesto político de trabalhadores podem se compor em uma síntese, de tal arte que a dificuldade em fazê-lo é um traço específico da obra de Flusser e de sua peculiar concepção de Homo ludens.

Um exemplo de leitura que se revela canônica para a compreensão do carnaval carioca e que pode se ajustar ao entendimento da greve dos garis em 2014 reside na obra de Roberto DaMatta. O antropólogo reconhece a dimensão de descolamento da realidade cotidiana associada ao Carnaval e identifica uma inversão na festa quando a elaboração temporal da rotina (viagens de ônibus cansativas em um dia normal de trabalho tornam-se, no carnaval, um divertimento), a delimitação do espaço (o centro de negócios da cidade transforma-se em um amplo salão de festejos, menos semelhante à metrópole moderna dos dias ordinários e mais próximo a uma vila medieval) e os domínios de moralidade e sociabilidade da casa e da rua não apenas se invertem, mas se encontram ${ }^{44}$.

É possível sugerir que, em um episódio como o movimento paredista dos profissionais de limpeza urbana, o parafuso damattiano recebe mais uma volta, de modo que, pela fresta da constatação de que "o carnaval engendra um movimento igualitário" 45 , em que a subjetividade do folião e suas arbitrárias escolhas (oscilantes desde o uso de vestimenta até a conduta sexual que pretende adotar, sem regras ou constrangimentos socionormativos) prevalecem sobre as hierarquias vigentes nos momentos cotidianos. É possível, a partir de DaMatta, propor a hipótese de que, em um dia normal de trabalho no Rio de Janeiro, as pessoas possivelmente não adeririam a uma marcha grevista protagonizada por trabalhadores da limpeza urbana. Professores, médicos, advogados, transeuntes em dia de folga, garçons ou motoristas provavelmente contemplariam a marcha dos garis com a distância, revestida ou não de simpatia, que a alteridade própria às diferenciações profissionais enseja. É, assim, precisamente a inversão que o ritual engendra o elemento apto a devolver à realidade (econômica e histórica) um protesto que se potencializa politicamente e ganha em solidariedade real a partir do impulso propiciado por uma dinâmica lúdica e por liames interpessoais ritualizados. É razoável supor que a adesão ritual-lúdica de pessoas invertidas em foliãs incide sobre a própria inversão, devolvendo o carnaval aos racionalizáveis conflitos sociais, mas em síntese que lhes empresta uma dinâmica própria, para a qual o lúdico se revela indispensável. Essa hipótese é apresentada sem o ânimo de discutir a obra damattiana ou de propor

44 DAMATTA, Roberto. Carnavais, malandros e heróis: para uma sociologia do dilema brasileiro. Rio de Janeiro: Rocco, 1997 .

45 Ibidem, p. I29. 
uma formulação rival à de Flusser para a compreensão do carnaval. O escopo é bem mais simples e reside em indicar que é possível vislumbrar a dinâmica ritualística do carnaval em compasso com um evento como a greve dos garis, de modo que o ponto cego ou o limite interpretativo reside menos em uma eventual contradição entre evento (greve) e rito (carnaval) para incidir sobre os limites e dificuldades que a peculiar leitura flusseriana empresta ao assunto, como abaixo se discute.

O caso da greve dos garis em 20I4, com efeito, é emblemático para infirmar a leitura flusseriana ${ }^{46}$ sobre o Brasil. Os elementos abaixo apresentados auxiliam na exposição desse argumento.

I) Quanto à diferença entre a alienação brasileira e a europeia atinente à economia inflacionária experimentada naquela, vê-se que o tempo histórico atual afasta tal premissa. O protesto dos garis, aliás, teve como força propulsora a obtenção de aumento salarial, dada a sua ausência nos parâmetros frequentes e ilusórios próprios ao período abordado em Fenomenologia do brasileiro.

2) Quanto ao caráter "externo" da alienação brasileira, de modo que até mesmo as formas de organização popular, como sindicatos, são importadas do norte, vê-se que a greve organizada contra a burocracia sindical, ao som de marchinhas e sob ritmo carnavalesco, afasta contundentemente tal visão. O Brasil contemporâneo, aliás, tem experimentado inúmeros movimentos grevistas sem apoio de direções sindicais.

3) Quanto ao fato de o proletário não se reconhecer como tal, projetando-se nos sonhos e no modo de vida do burguês, a greve dos garis, valendo-se da estética dos uniformes de trabalho e de pretensões como querer fazer as compras, indica o bastante para infirmar o que Flusser descreveu como o ser alienado que vive apenas às voltas com desejos de casa própria e signos de distinção.

4) No que tange à descoberta de nova realidade, a engendrar um "novo homem", "não histórico", na brincadeira do carnaval, Flusser igualmente fica sem lugar conceitual ou analítico diante de foliões que deixam seus blocos fantasiosos para aderirem ao cordão da greve dos garis, como ocorreu no Rio de Janeiro em 2014. Ademais, Flusser parece não notar que o que chama de "o brasileiro", tendo como referente aquele que brinca o carnaval, representa minoria populacional, já que as massas, nos quatro dias de folia, estão a coletar lixo, servir em restaurantes, trocar roupas de cama em hotéis, enfim, a trabalhar. Há uma gama de proletários que, provavelmente, não imerge no onírico carnavalesco, seja porque permanece a trabalhar como em ocasiões não festivas, seja por viver em cidades onde a própria festa encerra estratificações mais ostensivas do que no Rio de Janeiro (como em

46 O caso, embora singular, reúne elementos em vastidão suficiente para afastar a associação flusseriana entre carnaval, alienação e a-historicidade. Ademais, se Flusser parte de uma construção conceitual e genérica sobre o carnaval, aqui se procede a idêntica prática, à qual se acrescenta, porém, uma dimensão casuístico-empírica. O esteio socioepistêmico desta abordagem reside na definição de que os estudos de caso se revelam pertinentes para a identificação de "cisnes negros", ou situações singulares que afastam generalizações. FLYVBJERG, B. Making social science matter: why social inquiry fails and how it can succeed again. Cambridge: Cambrigde University Press, 20II. 
Salvador com a sua dinâmica de blocos privados) ou, ainda, porque não apreciam a festa (uma pesquisa nacional do Instituto Sensus, realizada em 2004, apontou que $57,4 \%$ dos brasileiros não gostam de carnaval) ${ }^{47}$. A "realidade profunda não histórica" que "sustenta" ${ }^{38}$ o proletário brasileiro não resiste, com efeito, a poucos minutos de observação etnográfica. A greve dos garis a afasta de modo ainda mais contundente ao desafiar os pressupostos flusserianos de uma perspectiva interna ao próprio carnaval do Rio de Janeiro.

5) Enfim, quanto à "aposta" de Flusser, vê-se que movimentos como os protestos de 2013 sob a Copa das Confederações da Fifa e, muito especialmente, a greve dos garis infirmam a um só tempo o surgimento do Homo ludens não histórico, ou a degeneração do proletário brasileiro em uma forma tardia de burocrata sindicalizado europeu.

Em suma, se Flusser pretendia contestar o conceito hegelo-marxista de alienação, o melhor caminho não seria a apresentação do caso brasileiro como "cisne negro" a negar-lhe universalidade e procedência. Ao contrário, a greve dos garis, aqui exposta de modo mais detalhado, é que se revela como "cisne negro" a negar pertinência aos atributos identificados no ser do brasileiro pelo fenomenólogo.

Se o lúdico e a ruptura com a alienação se encontram na efetiva realidade, se a necessidade econômica do "mamífero" flusseriano não se aparta do alegórico carnavalesco, mas dele se vale como ferramenta de luta, e se o ativismo movido pela consciência (ruptura com a alienação) de classe não diverge da brincadeira, então, como se pode discutir, em termos mais adequados a casos como o da greve dos garis, a relação entre estética e ativismo político? Esta é a questão que a derradeira seção, a seguir, pretende abordar.

\section{ESTÉTICA E ATIVISMO POLÍTICO}

A evidente relação entre estética e ativismo político, durante um longo período, foi pouco considerada pelas pesquisas acadêmicas. Por se situar na árida extensão do olhar que não comporta estereotipagem, tal interação esteve, muitas vezes, negligenciada. Contudo, com o rompante de reivindicações populares vividas no mundo, nos últimos anos, e no Brasil, marcadamente em 20I3, tem adquirido algum destaque e despertado observação mais acurada. Afinal, generalizações extremistas, desprovidas de mensuração e experimentação, por óbvio não explicam um Homo ludens que luta porque consciente de sua exploração, ainda que entremeado a festejos.

Para abordar estética, e sua indissociabilidade do ato político, uma recorrência válida é ao pensamento de Augusto Boal. Em A estética do oprimido (2009), esse escritor argumenta que as ideias dominantes em uma sociedade (aquelas das classes dominantes, opressoras) difundem-se e penetram pelos canais estéticos da palavra,

47 AGÊNCIA ESTADO. Pesquisa mostra: só 4I\% dos brasileiros gostam de carnaval. Agência Estado, I2 de fevereiro de 2004. Disponível em: <http://brasil.estadao.com.br/noticias/geral,pesquisa-mostra-so-4I-dosbrasileiros-gostam-de-carnaval,200402I2p2948>. Acesso em: Io dez. 2015.

48 FLUSSER, Vilém, op. cit. 
da imagem e do som, e que nesses mesmos domínios devem ser travadas "as lutas sociais e políticas em busca de sociedades sem opressores e sem oprimidos"49palavra, imagem e som empregados como "formas de rebeldia e ação, não passiva contemplação absorta”. Estética, para o ensaísta e dramaturgo que reinventou o teatro político no Brasil, "não é a ciência do Belo, como se costuma dizer, mas sim a ciência da comunicação sensorial e da sensibilidade. É a organização sensível do caos em que vivemos, solitários e gregários, tentando construir uma sociedade menos antropofágica"so.

Conformação a padrões preestabelecidos, redução de categorias a camas de Procrusto, que evidenciam intolerância ao exógeno, são estranhas ao argumento boaliano. Se Flusser sustenta distinções nas noções de alienação e proletariado para países com tradição no capitalismo e para aqueles aderentes ao novo modelo capitalista, negando historicidade aos últimos, Boal responde à provocação afirmando que "cada um é cada qual", cada época, país ou sociedade humana traz consigo sua verdade, determinada por sua cultura, considerada "a soma ativa de todas as coisas produzidas por qualquer grupo humano em um mesmo tempo e lugar, em sua relação com a natureza e com outros grupos sociais” 5 . Daí constatar que a aceitação universal de uma cultura - aqui referenciada em analogia a categorias como sendo a melhor, o parâmetro de validade para as demais, decorre de opressão universalmente exercida, sem contestação. E arremata: "criar nossa própria cultura, sem servidão àquelas que nos são impostas, é ato político e não apenas estético; ato estético, não apenas político!"’2.

O contraponto do argumento boaliano para o flusseriano sustenta-se, portanto, do ponto de vista da perspectiva adotada. Enquanto Flusser concebe o brasileiro como indivíduo alienado de si próprio e de sua realidade, que carece de fundamento e movimento históricos, equiparando-se a "grão de poeira de movimento browniano", Boal vislumbra no fenômeno físico das partículas macroscópicas que se movem em um determinado fluido de maneira aparentemente aleatória leis próprias que desconhecemos, o que não desmerece o movimento ou o reduz à insignificância. Trata-se do caos, que do nosso mundo é parte, forma de organização do universo e de tudo nele existente.

Existe e é reforçada no pensamento do filósofo tcheco, expresso em Fenomenologia do Brasileiro, a ideia de apreensões distintas sobre alienação, se comparado o proletário dos países históricos ao dos países neocapitalistas. Flusser é enfático ao sustentar que em países como o Brasil o proletariado carece de quaisquer formas de manifestação de sua identidade, esvaziadas em decorrência de seu aburguesamento. De fato, sindicatos burocratizados e partidos políticos que se orientam à disputa eleitoral não têm sido as formas de expressão da identidade do proletariado nos países neocapitalistas, notadamente em solo brasileiro. Isso, contudo, não autoriza dizer que há uma completa alienação dessa classe em tais países, pois, muitas vezes,

49 BOAL, Augusto. A estética do oprimido. Rio de Janeiro: Garamond, 2009, p. I5.

50 Ibidem, p. 3I.

5I Ibidem, p. 32.

52 Ibidem, p. 36. 
as alternativas de resistência à opressão que encontram estão fora de seus espaços representativos já institucionalizados. A greve dos garis cariocas descrita na seção anterior, evento recente ocorrido no Brasil no período assinalado pelo autor como de "alienação radical”, reforça tal objeção.

Diversamente do "novo homem" identificado no brasileiro, que trocou a realidade social e econômica pela realidade do jogo, os garis cariocas, alheios à festa carnavalesca no sentido esposado por Flusser, dela se aproveitaram para reivindicar direitos e dignidade, contestar sua fática vida real. Extrapolando a definição do carnaval como um terreno de fuga alienada, trabalhadores da limpeza urbana da cidade símbolo da folia aproveitaram-se do hipotético "período de recesso da esfera política e de suspensão das lutas e conflitos" para expor e contestar sua nada lúdica realidade e, confrontando forças antagônicas, impulsionaram mudanças em sua condição. Partindo da análise flusseriana, não coincidem os fatos aduzidos ao sentido atribuído.

O filósofo tcheco observou, mas não enxergou. Quis transpor um estado efusivo momentâneo vivenciado no Brasil, como o carnaval, para a totalidade da vida do brasileiro. Extraiu de uma observação pontual uma generalização, estatuiu dogmas a partir de uma realidade que é sujeita a múltiplas determinações. Desconsiderou que indivíduos usualmente "reempregam um sistema que, muito longe de lhes ser próprio, foi construído e propagado por outros, e marcam esse reemprego por "super-ações"53. De modo invertido, acertou Flusser ao constatar que "em todos os cantos do país é possível sentir-se a musculatura do gigante que desperta”54. No caso brasileiro apresentado, "o gari acordou" foi um dos cânticos entoados pelos trabalhadores grevistas da Companhia Municipal de Limpeza Urbana. Antes de um "gigante" estatal ou civilizatório, quem se agigantou foi precisamente o proletário, "caboclo urbanizado" 55 de Flusser.

Lançar-se às ruas, espaços não institucionalizados, protestando por melhorias de vida e contra formas de dominação e reclamando alguma participação política mais direta, sem a obrigatoriedade de intermediários, requer empunhar palavras, imagens e sons, combiná-los à disposição do corpo, sincronizar gestos e movimentos, enfim, valer-se dos canais estéticos de que dispõem. Para compreender os novéis protestos, um exercício necessário é não se deter apenas no conteúdo: há muito a ser apreendido da forma. Uma particularidade que ressai desse novo agir, identificada como atributo de expansão da dinâmica dos protestos registrados até os primeiros anos deste século, é o deslocamento da ação política em direção às intervenções próximas à vida cotidiana.

No ponto aqui colocado, uma digressão pelos protestos realizados nos últimos cinquenta anos - do limiar da ditadura militar, com foco nos marcos estéticos e culturais do ativismo político empreendido - corrobora para a apreensão da estética das lutas sociais da atualidade e do contexto histórico em que evoluíram.

\footnotetext{
53 CERTEAU, Michel de. A invenção do cotidiano: artes de fazer. Vozes: Petrópolis, I994, p. 78.

54 FLUSSER, Vilém, op. cit.

55 Ibidem.
} 
Borelli et al.56, na formatação do estado da arte das ações estético-culturais e novas práticas políticas envolvendo jovens urbanos brasileiros, destacaram as seguintes características no recorte temporal proposto:

I) nos anos I960, as mobilizações políticas atrelaram-se aos movimentos estudantis e ao campo cultural, das quais ressaem: desenvolvimento da produção artística de ação política de esquerda; influência do Cinema Novo, do Tropicalismo e da Jovem Guarda, vinculada à televisão; introdução da cultura pop no Brasil; realização de festivais de música associados às emissoras de TV;

2) nos anos I970, as mobilizações políticas, bastante atreladas aos movimentos estudantis, enfatizaram a resistência à ditadura militar, com o apelo a práticas de guerrilha urbana inspiradas na revolução cubana; a diversidade marcou a preferência musical da juventude (MPB, Onda Disco, música black, funk e soul); o estímulo à liberação sexual como forma de expressão; revolução comportamental hippie;

3) na década de I980, apesar da retração dos movimentos estudantis, os jovens foram às ruas, em conjunto com amplos segmentos sociais, em campanha popular pelo voto direto para presidente da República, realizando barulhentas passeatas em que trajavam camisetas verde-amarelas com os dizeres "Eu quero votar para presidente”; com a abertura democrática, a ação, antes concentrada no ambiente universitário, transbordou para a experiência cotidiana; surgiram os primeiros adeptos do movimento dark e os skinheads; o movimento punk consolidou-se nas grandes cidades e o rap fixou-se inicialmente em São Paulo com o Movimento Hip-Hop organizado, além de emergir a atuação de jovens grafiteiros e pichadores;

4) nos anos I990, ressai o movimento dos "caras-pintadas", dotado de forte apelo estético (rostos pintados de verde e amarelo), que ocupou as ruas para protestar contra a corrupção no governo;

5) nos anos 2000 , merecem destaque o reaparecimento do movimento estudantil universitário, a ampliação do uso político da tecnologia - emergência do ciberativismo na organização de ações juvenis (discussões sobre o uso do espaço urbano e as atividades colaborativas em prol de softwares abertos, internet livre e compartilhamento de arquivos gratuitos) - e a maior visibilidade das culturas juvenis das periferias urbanas, possibilitada pelo aparecimento de novas formas de participação e intervenção sociais (rádios comunitárias, produção de fanzines, vídeos e saraus literários).

Os protestos atuais avançam sobre a petrificada lógica das burocracias partidárias. São pró-PSOE - Partido Socialista Operário Espanhol e anti-PSOE na Espanha. São pró-Pasok - Movimento Socialista Pan-helênico e anti-PASOK na Grécia. São pró-PT - Partido dos Trabalhadores e anti-PT no Brasil. Nem por isso, definem-se como niilismos ou somas cacofônicas de alaridos, como a ciência política

56 BORELLI, S. H. S.; ROCHA, R. L. M.; OLIVEIRA, R. C. A. ; LARA, M. R. Jovens urbanos, ações estético-culturais e novas práticas políticas: estado da arte (I960-2000). In: ALVARADO, Sara Victoria; VOMMARO, Pablo (Org.). Jóvenes, cultura y política en América Latina: algunos trayectos de sus relaciones, experiencias y lecturas (I960-2000). I. ed. Rosario: Homo Sapiens Ediciones, 2010, p. 293-323. 
tradicional tende a classificá-los ${ }^{57}$. No Brasil ${ }^{58}$, coletivos como o Movimento Passe Livre (MPL), movimentos como a Marcha Mundial das Mulheres, organizações estudantis como a Assembleia Nacional dos Estudantes - Livre (Anel) e partidos políticos como o Partido Socialismo e Liberdade (PSOL) e o Partido Socialista dos Trabalhadores Unificado (PSTU) atestam que, nas ruas, há muito mais organização e coordenação do que uma primeira impressão pode sugerir. Há, igualmente, uma certa constância quanto aos propósitos que levam pessoas às ruas em todo o mundo. Como constatam Barker et al.:

Parece apropriado, então, perguntar se há significativas conexões entre essas erupções de protestos populares. Grandes somas daqueles ativamente participantes, do Cairo a Atenas, de Nova Iorque a Santiago, acreditam que sim. E as conexões se delineiam na preocupação com a combinação de austeridade, desigualdade crescente, despossessão de direitos e garantia, e um défice democrático que possibilita a imposição de tudo isso por pequenas elites, sob um pano de fundo da maior crise econômica global desde os anos 30 do século XX59.

Os novos protestos, destarte, não são marcados por desorganização, ultraindividualização ou falta de propósitos claros. Definem-se, sim, pela inventividade e espontaneidade; preocupam-se com a performance dos corpos, com roupas, cabelos, sonoridades, narrativas, tecnologias. Não se trata, contudo, de uma fuga pela expressão artística, mas de um enfrentamento, um desvelar da realidade em direção à sua superação, à emancipação.

O filósofo Costas Douzinas, ao comparar os protestos da Grécia atual com as convenções partidárias no mesmo país, descobre uma crucial diferença estético-política. Nas convenções, as lideranças falam em um palanque instalado na praça, as massas aplaudem, silenciam-se e compõem a força expressiva do ato por meio de sua passividade. Nas ocupações de praças por movimentos antiausteridade,

57 O cientista político brasileiro Wanderley Guilherme dos Santos assim define os protestos de 2013 no Brasil: "Não existem, contudo, vozes das ruas, apenas alaridos. Não foram as cartolinas pintadas que levaram as primeiras multidões às passeatas, elas surgiram algum tempo depois das marchas em busca de um porquê das próprias marchas. A seco, melhoras genéricas da saúde pública ou da educação não estimulam o deslocamento de dezenas de milhares de manifestantes. Reforma política, então, nem em cartolina apareceu. [...] Participam hoje dos protestos, fora os incautos e ingênuos que sempre existem e lhes emprestam ar de legitimidade, grupos anômicos de jovens de algumas posses, grupos neonazistas e pré-fascistas, organizações niilistas nacionais e internacionais, além das gangues ordinárias de ladrões e assaltantes”. SANTOS, Wanderley Guilherme. Anomia niilista. Valor econômico, 26 de julho de 20I3. Disponível em: <http://www.valor.com.br/cultura/32II228/ anomia-niilista>. Acesso em: I9 jun. 2014.

58 O papel da Syriza nos protestos gregos, das organizações juvenis ou mesmo islâmicas na "primavera" do Egito e das associações estudantis organizadas na Revolta dos Pinguins chilenos são outros exemplos de que, no atual momento histórico, há mais do que individualidades dispersas nas ruas.

59 BARKER, Colin et al. Marxism and social movements: an Introduction. In: BARKER, Colin et al. (Ed.). Marxism and social movements. Boston: Brill, 20I3, p. 2 (tradução nossa). 
todos pintam, fazem grafites, tocam instrumentos e dialogam como público e artistas, uns em relação aos outros. A praça, afirma Douzinas,

[...] encenou a soberania popular na forma do teatro público. Fez lembrar o chamado de Friedrich Schiller para uma revolução estética a acompanhar uma insurreição política [...] Stasis Syntagma ${ }^{60}$ foi um "evento" de estética política que mudou tanto o significado da política, como da arte pública ${ }^{6 \mathrm{I}}$.

Se na Grécia a subversão política toma a forma do teatro, o caso brasileiro, como visto com a greve dos garis, traz experiência análoga com o carnaval. Do mesmo modo que as convenções partidárias mencionadas por Douzinas, os congressos da União Nacional dos Estudantes (UNE) e da Central Única dos Trabalhadores (CUT) ou os comícios do PT nos anos I980 e I990 eram espaços onde o "palanque", a "direção" e toda fonte de autoridade a irradiar palavras de ordem, momentos de aplauso, discursos e tempo de fala seguiam rígida e clara verticalidade. Momentos como a greve dos garis ou as marchas de 2013 têm, lado outro, carros de som em que todos falam, seguindo-se apenas as ordens de inscrição, diferentemente dos comícios petistas dos anos I990, em que só falavam aqueles que compunham a mais alta burocracia partidária, além de "artistas" com visibilidade midiática. Tampouco operam como nos congressos da UNE e da CUT, onde a "defesa de propostas" em plenário era, inexoravelmente, exercida apenas pela burocracia vinculada a partidos políticos.

As formas de expressão artística em momentos como a greve dos garis não seguem o "músico no palanque", como nos comícios das campanhas de Lula à presidência da República. Exatamente como na Grécia descrita por Douzinas, aqui, nos protestos atuais, todos criam e todos apreciam a criação estética de cada um.

Assim ocorreu no carnaval de 2014 do Rio de Janeiro. Na esteira do que Flusser mencionou ser "um recorte festivo no tempo que dá sentido ao ano"62, os garis cariocas, em um arroubo de criatividade - à qual estamos condenados, afirmava Boal -, trajando, em sua maioria, o uniforme cor laranja, ostentavam faixas e cartazes com dizeres como "O prefeito quer fazer a Copa. Os garis querem fazer as compras", "Não somos lixo", "Os garis também acordam. Chega de covardia”, "Cidade Maravilhosa. Nós contribuímos para isso”. Na paralisação empreendida, apropriaram-se da linguagem do carnaval e dos desfiles das escolas de samba - versos ritmados, cadência do samba, enredo, bateria improvisada com latões, harmonia, evolução, conjunto -, transformando-a em um canto de resistência, "sem que essa metamorfose interna comprometa a sinceridade com a qual pode ser acreditada, nem a lucidez com a qual, aliás, se veem as lutas e as desigualdades sob a ordem estabelecida"63.

Há, portanto, um protagonismo do proletariado brasileiro que se destaca pela utilização de sistemas impostos para resistir à lei histórica de um estado de fato e

60 Nome do local onde ocorreram os protestos (nota nossa).

6I DOUZINAS, Costas. Philosophy and resistance in the crisis. Cambridge: Polity, 20I3, p. I65 (tradução nossa).

62 FLUSSER, Vilém, op. cit.

63 CERTEAU, Michel de, op.cit., p. 78-79. 
suas legitimações dogmáticas, de modo que "mil maneiras de jogar/desfazer o jogo do outro, ou seja, o espaço instituído por outros, caracterizam a atividade, sutil, tenaz, resistente, de grupos que, por não ter um próprio, devem desembaraçar-se em uma rede de forças e de representações estabelecidas"64. Negar a realidade, ao contrário de explicá-la, é falseá-la. Adereçar o carnaval com vestes de alienação não mais é que alhear do significante seu significado.

A realização do carnaval, como os garis do Rio de Janeiro ensinam à filosofia burguesa de matriz europeia, consiste em sua composição dialética e engajada com a realidade, imiscuindo-se e posicionando-se sobre os conflitos do tempo presente. Mais do que não histórico e alienado em direção a uma nova realidade lúdica, o carnaval pode ser, precisamente, a arma lúdica de luta para a transposição de uma história de alienação na realidade de mesma e constante opressão.

\section{SOBRE OS AUTORES}

FRANCISCO MATA MACHADO TAVARES é professor adjunto do Programa de Pós-graduação em Ciência Política da Universidade Federal de Goiás - UFG. Coordenador do Programa de Pós-Graduação em Ciência Política. Coordenador do Proluta/UFG - Programa de Pesquisas sobre Ativismo em Perspectiva Comparada.

E-mail: franciscotavares@ufg.br

ELLEN RIBEIRO VELOSO é mestre em Ciência Política pela UFG. Pesquisadora do Proluta/UFG. Alumni bolsista da Berlin Summer School in Social Sciences. E-mail: ellen_rv5@hotmail.com

\section{REFERÊNCIAS BIBLIOGRÁFICAS}

AGÊNCIA ESTADO. Pesquisa mostra: só 4I\% dos brasileiros gostam de carnaval. Agência Estado, I2 de fevereiro de 2004. Disponível em: 〈http://brasil.estadao.com.br/noticias/geral,pesquisa-mostra-so4I-dos-brasileiros-gostam-de-carnaval,200402I2p2948〉. Acesso em: Io dez. 2015.

ALONSO, Angela. As teorias dos movimentos sociais: um balanço do debate. Lua Nova [online], n. 76, 2009, p. 49-86. Disponível em: 〈http://dx.doi.org/Io.I590/SoI02-64452009000I00003〉. Acesso em: 4 jul. 2014. BARKER, Colin et al. Marxism and social movements: an introduction. In: BARKER, Colin et al. (Ed.). Marxism and social movements. Boston: Brill, 20I3, p. I-4I.

$64 \quad$ Ibidem, p. 79 
BOAL, Augusto. A estética do oprimido. Rio de Janeiro: Garamond, 2009.

BOURGEOIS, Bernard. O pensamento político de Hegel. Tradução de Paulo Neves da Silva. São Leopoldo: Unisinos, 2000.

BORELLI, S. H. S. et al. Jovens urbanos, ações estético-culturais e novas práticas políticas: estado da arte (I960-2000). In: ALVARADO, Sara Victoria; VOMMARO, Pablo (Org.). Jóvenes, cultura y política en América Latina: algunos trayectos de sus relaciones, experiencias y lecturas (I960-2000). I. ed. Rosario, Argentina: Homo Sapiens Ediciones, 20I0, p. 293-323.

BRINGEL, Breno; PLEYERS, Geoffrey. Junho de 20I3... Dois anos depois: polarização, impactos e reconfiguração do ativismo no Brasil. Nueva Sociedad: Democracia e Politica en América Latina, vol. especial, nov. 20I5. Disponível em: 〈http://nuso.org/media/articles/downloads/COYI_Bringel_Pleyers.pdf〉. Acesso em: I2 dez. 2015.

BYRNE, David T. The victory of the proletariat is inevitable: the millenarian nature of marxism. Kritike, V. 5, n. 2, dec. 20II, p. 59-67.

CERTEAU, MICHEL DE. A invenção do cotidiano: artes de fazer. Vozes: Petrópolis, I994.

CHITTY, Andrew. Recognition and social relations of production. Historical Materialism, n. 2, Verão, I998, p. 57-97.

. Species-being and Capital. In: CHITTY, Andrew; IVOR, Martin (Ed.). Marxism and contemporary philosophy. Londres: Palgrave, 2009. p. I23-I42.

DAMATTA, Roberto. Carnavais, malandros e heróis: para uma sociologia do dilema brasileiro. Rio de Janeiro: Rocco, I997.

DOUZINAS, Costas. Philosophy and resistance in the crisis. Cambridge: Polity, 2013.

FLUSSER, Vilém. Fenomenologia do brasileiro. Organização de Gustavo Bernardo. Rio de Janeiro: UERJ, I998. Transcrição literal disponível em: <http://textosdevilemflusser.blogspot.com.br/〉. Acesso em: Io jul. 20I4.

FLYVBJERG, B. Making social science matter: why social inquiry fails and how it can succeed again. Cambridge: Cambrigde University Press, $20 I I$.

FREITAS, Jânio de. O Papel da PM na greve dos garis. Blog do Nassif, 20I4. Disponível em: <http://jornalggn. com.br/noticia/o-papel-da-pm-na-greve-dos-garis-por-janio-de-freitas >. Acesso em: Io jul. 2014.

GARCIA, Rafael Tsavko. Greve dos Garis no Rio de Janeiro: da luta à vitória. Global Voices, 20I4. Disponível em: 〈http://pt.globalvoicesonline.org/20I4/o3/II/greve-de-garis-no-rio-de-janeiro-da-luta-a-vitoria/ >. Acesso em: Io jul. de 20I4.

HUIZINGA, Johan. Homo ludens. Tradução de João Paulo Monteiro. São Paulo: Perspectiva, 2000.

KOJĖVE, Alexandre. Introdução à leitura de Hegel. Tradução de Estela dos Santos Abreu. Rio de Janeiro: Contraponto, 2002.

MANENTI, Caetano. Garis usam 4 dias de carnaval para movimento histórico no Rio de Janeiro. Sul 2I, 5 de março de 20I4. Disponível em: <http://www.sul2I.com.br/jornal/garis-usam-os-quatro-dias-docarnaval-para-movimento-historico-no-rio-de-janeiro/>. Acesso em: Io jul. 20I4.

MARX, Karl. A crítica da filosofia do direito de Hegel. Tradução de Rubens Enderle e Leonardo de Deus. São Paulo: Boitempo, 2005.

SAMPAIO JÚNIOR, Plínio de Arruda. Jornadas de junho e revolução brasileira. Interesse nacional, São Paulo, ano 6, n. 23, out.-dez., 20I3, p. 57-66.

SANTO AGOSTINHO. Confissões. Tradução de J. Oliveira Santos e A. Ambrósio de Pina. Bragança Paulista: São Francisco, 2003.

SANTOS, Wanderley Guilherme. Anomia niilista. Valor econômico, 26 de julho de 20I3. Disponível em: 〈http://www.valor.com.br/cultura/32II228/anomia-niilista〉. Acesso em: I9 jun. 20I4. 
SINGER, André. Brasil, junho de 20I3: classes e ideologias cruzadas. Novos Estudos: Cebrap, n. 97, nov. 20I3, p. 23-40.

SWEEZY, P. M. Marx and the proletariat. In: JESSOP, Bob (Ed.). Karl Marx's social and political theory. v. 2. Londres: Routledge, I990, p. 228-240.

TAVARES, Francisco Mata Machado. Para além da democracia deliberativa: uma crítica marxista à teoria política habermasiana. Tese (Doutorado). Departamento de Ciência Política, Universidade Federal de Minas Gerais, 20I3. Disponível em: <http://marxismo2I.org/estado-e-democracia/〉. Acesso em: I8 jun. 2014 .

WOOD, Ellen Meiksins. Democracy against capitalism. Renewing Historical Materialism. Cambridge: Cambridge University Press, I999.

WOOD, Ellen. Liberty and property: a social history of western political thought from the Renaissance to Enlightenment. Londres: Verso, 2012. 